\title{
The structure, biological activity and biogeochemistry of cryoconite aggregates upon an Arctic valley glacier: Longyearbreen, Svalbard
}

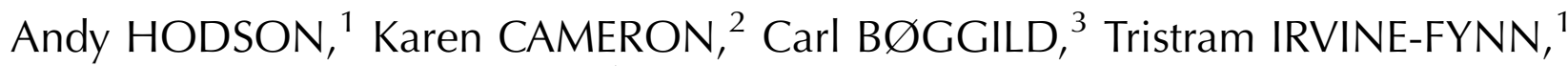 \\ Harry LANGFORD, ${ }^{1,4}$ Dave PEARCE, ${ }^{5}$ Steven BANWART ${ }^{4}$ \\ ${ }^{1}$ Department of Geography, University of Sheffield, Winter Street, Sheffield S10 2TN, UK \\ E-mail: A.J.Hodson@Sheffield.ac.uk \\ ${ }^{2}$ Department of Animal and Plant Sciences, University of Sheffield, Winter Street, Sheffield S10 2TN, UK \\ ${ }^{3}$ The University Centre in Svalbard (UNIS), PO Box 156, NO-9171 Longyearbyen, Norway \\ ${ }^{4}$ Kroto Research Institute, University of Sheffield, Broad Lane, Sheffield S3 7HQ, UK \\ ${ }^{5}$ British Antarctic Survey, Natural Environment Research Council, Madingley Road, Cambridge CB3 OET, UK
}

\begin{abstract}
Glacier surfaces support unique microbial food webs dominated by organic and inorganic debris called 'cryoconite'. Observations from Longyearbreen, Spitsbergen, show how these aggregate particles can develop an internal structure following the cementation of mineral grains (mostly quartz and dolomite) by filamentous microorganisms. Measurements of carbon and dissolved $\mathrm{O}_{2}$ show that these microorganisms, mostly cyanobacteria, promote significant rates of photosynthesis (average $17 \mu \mathrm{gC} \mathrm{g}^{-1} \mathrm{~d}^{-1}$ ) which assist aggregate growth by increasing the biomass and producing glue-like extracellular polymeric substances. The primary production takes place not only upon the surface of the aggregates but also just beneath, due to the translucence of the quartz particles. However, since total photosynthesis is matched by respiration (average $19 \mu \mathrm{gC}^{-1} \mathrm{~d}^{-1}$ ), primary production does not contribute directly to cryoconite accumulation upon the glacier surface. The microorganisms therefore influence the surface albedo most by cementing dark particles and organic debris together, rather than simply growing over it. Time-lapse photographs show that cryoconite is likely to reside upon the glacier for years as a result of this aggregation. These observations therefore show that a better understanding of the relationship between supraglacial debris and ablation upon glaciers requires an appreciation of the biological processes that take place during summer.
\end{abstract}

\section{INTRODUCTION}

The presence of biologically active debris or 'cryoconite' upon glacier ice has been known for some time (Fountain and Tranter, 2008) and there is now an emerging dataset that characterizes the range of microorganisms present (Hodson and others, 2008, for a review). Important work by Takeuchi, Kohshima and co-workers has described how cryoconite resembles quasi-spherical, mineral-rich aggregate particles that form on the glacier surface in a range of environments (e.g. Kohshima and others, 1993; Takeuchi and others, 2000, 2001b; Takeuchi, 2002). Since biological processes are involved in the formation of these aggregates, they also prolong the residence time of fine debris upon the glacier surface. This results in spatial variations in the albedo of cryoconite-covered glaciers, so a partly biological control upon glacier ablation can be proposed (e.g. Kohshima and others, 1993; Takeuchi and others, 2001b; Hodson and others, 2007; Takeuchi, 2009; Bøggild and others, 2010). However, a better understanding of this control is hampered by there being virtually no studies of the formation and persistence of cryoconite aggregates upon glacier ice surfaces. Fountain and others (2004) and MacDonell and Fitzsimons (2008) have considered the impact of cryoconite aggregates upon the supraglacial drainage system of cold Antarctic glaciers in the McMurdo Dry Valleys, and both Kohshima and others (1993) and Takeuchi and others (2000) have monitored the fate of cryoconite holes under different melting conditions in central Asia. However, the full life cycle of cryoconite aggregates, from formation to removal or destruction, has yet to be quantified. This makes it impossible to construct meaningful, physically based models of the impact of cryoconite upon melt and biogeochemical cycles without assuming a steady-state population. For example, Hodson and others (2007) derived a snapshot of the extent of cryoconite across a glacier on Svalbard using ground-based and remote-controlled airborne photogrammetry and assumed that the distribution of the aggregates was relatively uniform throughout the ablation season and from one year to the next. However, the mapping work showed that cryoconite was concentrated within streams in the ablation area and isolated patches known as cryoconite holes in the accumulation area. Therefore, removal of the debris by meltwater transfer into streams almost certainly takes place during the summer, and measurements of this process are required to see how the distribution, albedo and melt rate of the glacier change as a result.

The dynamics of cryoconite distribution over glaciers are also likely to be linked to the carbon balance of this poorly understood ecosystem (Hodson and others, 2007). Anesio and others (2009) argued that cryoconite ecosystems are able to fix globally significant carbon fluxes from the atmosphere via photosynthesis, so there is also a need to assess the impact of this biomass change upon ice albedo. This is because growth of the aggregates will reduce glacier surface albedo unless kept in check by the heterotrophic community (mostly bacteria) and physical removal by meltwater. Our work, presented here, therefore examines the dynamics, biological activity and structure of cryoconite 


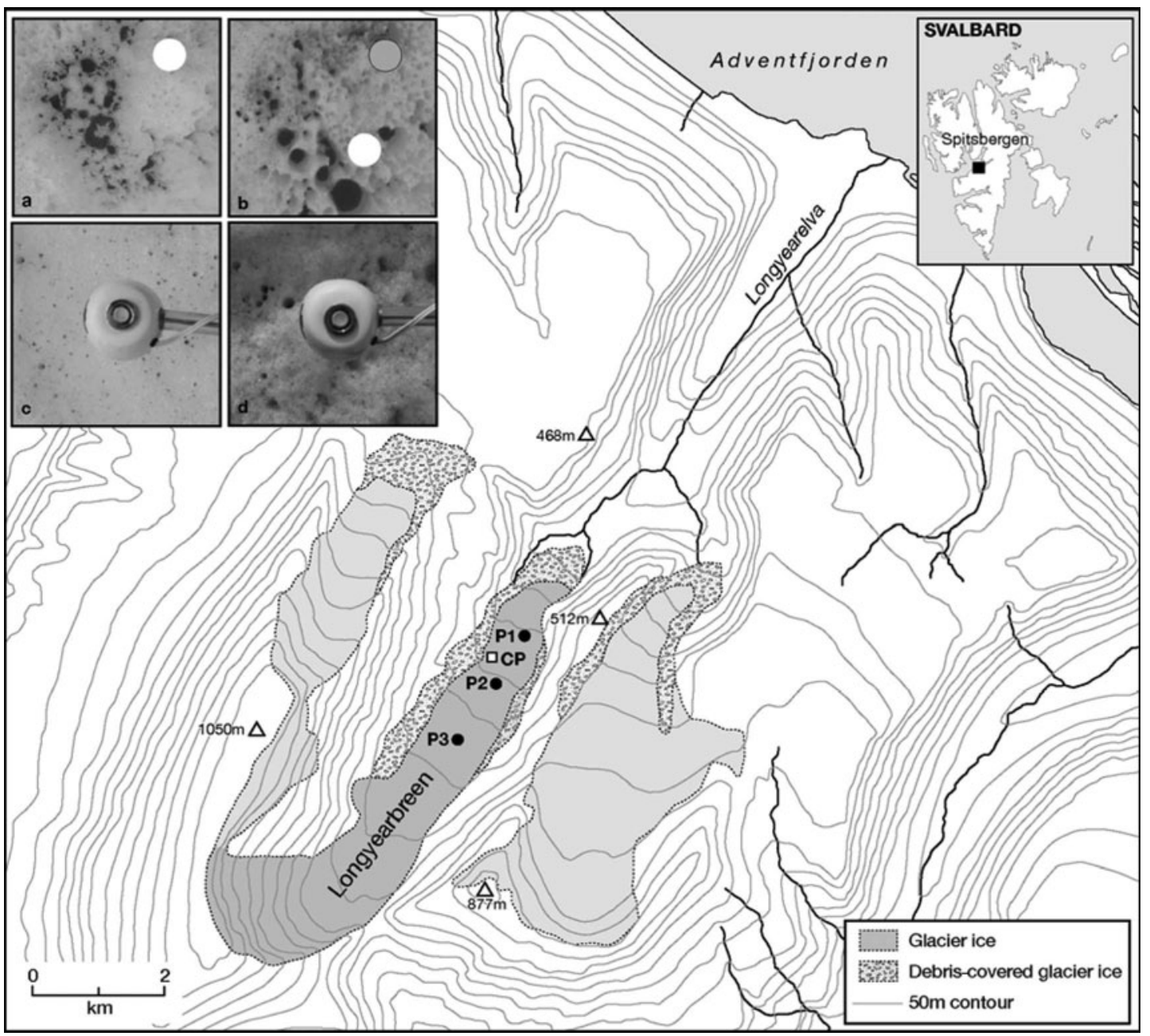

Fig. 1. Longyearbreen and the principal sites of interest during the investigation. P1-3 are the snow-pit locations and CP is the Cryoplot. Insets (a) and (b) are the initial and near-final states respectively of the Cryoconite Patch. Insets (c) and (d) are the initial and near-final states respectively of the Control Patch. Dates are DOY 202-222. The white $47 \mathrm{~mm}$ calibration disc is also shown (its position changed, hence the grey disc).

upon Longyearbreen, a valley glacier in Svalbard, in order to improve our understanding of these biological and physical process dynamics. First, the mass transfer of cryoconite across a small ice patch and its subsequent impact upon albedo are reported at the small plot scale using a time-lapse camera and radiation sensors. Second, measurements of the carbon balance of cryoconite immersed in supraglacial meltwater and nutrient-rich slush are used to assess primary production and heterotrophic respiration. Third, the internal structure and composition of the cryoconite used in these experiments are explored using a range of destructive analyses in order to seek a better understanding of the aggregation process that formed them.

\section{METHODOLOGY}

This research was conducted upon Longyearbeen, a small cold-based glacier adjacent to the Longyearbyen community in Svalbard $\left(78^{\circ} 10^{\prime} 49^{\prime \prime} \mathrm{N}, 15^{\circ} 30^{\prime} 21^{\prime \prime} \mathrm{E}\right)$. The glaciological and geochemical characteristics of the glacier have been described by Yde and others (2008). In our study, a novel combination of physical, chemical and biological measurements were collected between 17 July and 16 August 2008 at various points across the glacier ablation area. These included three snow-pit sites, where we assessed biological production associated with an unseasonally late snow cover, and also an instrumented small plot of glacier ice, hereafter referred to as the 'Cryoplot'. The observations collected at the Cryoplot are described in detail below, before the biological production measurements conducted at all sites are explained.

\section{Plot-scale observations of cryoconite dynamics}

A Kovacs ice drill was used to construct a frame using $40 \mathrm{~mm}$ aluminium tubing over two $1 \mathrm{~m}^{2}$ patches of glacier ice typical of the early-summer glacier surface: one clear of visible debris and the other covered by a hydrologically connected series of cryoconite holes $\sim 1-10 \mathrm{~cm}$ wide (and $\sim 5 \mathrm{~cm}$ deep at first; Fig. 1). Hereafter, we refer to these surfaces as the 'Control Patch' and 'Cryoconite Patch' respectively. Measurements of ablation and shortwave radiation were collected at both patches, the latter being achieved by using cross-calibrated up- and down-looking pyranometers (Middleton, UK and Skye Instruments, UK) that allowed calculation of albedo. The Cryoconite Patch also had a time-lapse camera positioned over it, allowing hourly images of the features to be captured using a Pentax Optio WP30 digital camera. The time-lapse images were captured as 7-megapixel JPEG files $0.5-1 \mathrm{~m}$ above the ice surface (the distance increasing as the ice ablated). Images of the Control 
Patch were collected opportunistically. However, this area of ice gradually metamorphosed into a patch of small $(0.5 \mathrm{~cm}$ diameter), deep (up to $15 \mathrm{~cm}$ ) cryoconite holes (Fig. 1).

To determine representative cryoconite granule size and cryoconite-covered area at the Cryoconite Patch, imageanalysis tools within ImageJ software were used. First, granules collected from sites across the glacier ablation area were photographed in a Petri dish underlain by $2 \mathrm{~mm}$ graph paper. After thresholding the images to isolate the cryoconite, Imagej's 'analyse particles' tool was used to automatically estimate the Feret diameter (longest object axis) for 90 discrete cryoconite granules. Repeat analyses then allowed estimation of uncertainties in this procedure. For the time-lapse images at the Cryoconite Patch, analysis was undertaken in order to quantify area coverage, rather than the Feret diameter. Image resolution was first determined using a circular $47 \mathrm{~mm}$ white disc (Fig. 1), which was used as a scale reference as ablation lowered the ice surface from the camera. With known image resolution, we were able to quantify the areal distribution of cryoconite in a constant $0.2 \mathrm{~m} \times 0.2 \mathrm{~m}$ region of interest $(\mathrm{ROI})$ at the image centre point. Uncertainties in area again arose from userdefined subjectivity in the choice of threshold. Therefore the process was repeated three times and the mean reported, along with an estimate of uncertainty $(2 \sigma$, where $\sigma$ was the standard deviation of cryoconite area estimates). A sequence of 41 images was processed individually due to variations in threshold levels required by changing light conditions. Full details of the image-processing methods and related uncertainties described here are reported by Irvine-Fynn and others (2010).

\section{Light and dark incubations}

A combination of batch incubations (both light and dark) and water chemistry observations was used to evaluate biogeochemical conditions and their relationship with biological activity. Initially, slush from the base of the snowpack was incubated at three different locations (pits 1-3; Fig. 1) so that biological activity could be assessed prior to the subaerial exposure of the cryoconite on the ice. Thereafter, cryoconite sampled from across the ablation area of the glacier was incubated next to the Cryoplot. The initial cryoconite incubations were conducted using basal snowmelt from pit 3, whilst subsequent incubations made use of supraglacial ice melt. Additional samples of this slush and supraglacial ice melt were also used to assess controls upon the natural composition of runoff.

Light and dark incubations were conducted using glass flasks (70 and $200 \mathrm{~mL}$ ) with similar area/volume ratios and white, airtight plastic lids. Shading by the lid did not occur due to the low angle of the sun and the width/depth dimensions of the vessel. Dark incubations were conducted in foil-wrapped bottles. Since most cryoconite aggregates occupied a near-uniform layer within holes and streams (Hodson and others, 2007), care was taken not to add too many to the flask, leaving a layer just one to two grains deep. Thus the areal mass distribution within the incubations was broadly the same as that observed within deposits upon the ice surface, $\sim 0.125 \mathrm{~g} \mathrm{~cm}^{-2}$. Only in cases where cryoconite accumulated in cracks in the ice was there evidence for much thicker deposits.

Incubations were undertaken between 17 July and 16 August 2008 (i.e. day of year (DOY) 199-229). The duration of the incubations varied between 1 and 3 days upon the ice. The light incubations were emplaced at a level below the ice surface that matched the depth of nearby cryoconite holes, typically $4 \mathrm{~cm}$. The foil-wrapped dark incubations were placed at the same depth, but were buried with ice chips. When the incubation ended, a $30 \mathrm{~mL}$ aliquot of water was removed using a gas-tight syringe for total dissolved carbon analysis. A dissolved oxygen sensor was then immediately immersed into the water for three measurements, with very gentle agitation between each one. The water was then filtered through a pre-rinsed (once with deionized water and twice with sample) $0.2 \mu \mathrm{m}$ Whatman cellulose nitrate filter paper and frozen until analysis in the laboratory (see below) about 2 months later. The filter paper was allowed to drain on absorbent paper and then frozen as well.

\section{Calculation of ecosystem productivity from incubation data}

Light and dark incubations were employed to assess net community production, respiration (i.e. $\mathrm{CO}_{2}$ production) and primary production $\left(\mathrm{CO}_{2}\right.$ sequestration). The functional relation between these terms, defined as NEP, $R$ and PP respectively, is given by:

$$
\mathrm{NEP}=\mathrm{PP}-R
$$

where NEP and $R$ are estimated from the light and dark incubations respectively, allowing PP to be determined by difference. Typically, the units for each term are $\mu \mathrm{gC} \mathrm{m}^{-2} \mathrm{~d}^{-1}$ for most aquatic environments. However, we use $\mu g \mathrm{Cg}^{-1} \mathrm{~d}^{-1}$ (where $g$ is the unit for the dry mass of cryoconite), since an overwhelming majority of ecosystem activity has been found to be associated with the benthic aggregate layer and not the transient water layer above it (Hodson and others, 2007; Stibal and Tranter, 2007; Anesio and others, 2009). However, since the slush incubations lacked a quantifiable mass of aggregates or other debris, we expressed these results using units of $\mu g \mathrm{CL}^{-1} \mathrm{~d}^{-1}$.

For all incubations, changes in the total dissolved inorganic carbon (TDIC) of the light and dark incubation waters ( $\triangle \mathrm{TDIC}^{\text {light }}$ and $\triangle \mathrm{TDIC}^{\text {dark }}$ ) may be substituted directly for NEP and $R$ respectively, once they have been corrected for the dissolution of carbonate (which is present as calcite and dolomite according to Yde and others, 2008). This results in the following equations for the terms in Equation (1):

$$
\begin{gathered}
\mathrm{NEP}^{\mathrm{TDIC}}=\Delta \mathrm{TDIC}^{\text {light }}-[\Delta \mathrm{Ca}+\Delta \mathrm{Mg}]^{\text {light }} \\
R^{\mathrm{TDIC}}=\Delta \mathrm{TDIC}^{\text {dark }}-[\Delta \mathrm{Ca}+\Delta \mathrm{Mg}]^{\text {dark }} \\
\mathrm{PP}^{\mathrm{TDIC}}=\left(\Delta \mathrm{TDIC}^{\text {light }}-[\Delta \mathrm{Ca}+\Delta \mathrm{Mg}]^{\text {light }}\right)-R^{\mathrm{TDIC}} .
\end{gathered}
$$

The units here are $\mu \mathrm{mol} \mathrm{g}{ }^{-1} \mathrm{~d}^{-1}$ for all terms, and $[\Delta \mathrm{Ca}+$ $\Delta \mathrm{Mg}$ ] represents the production of TDIC by carbonate dissolution $\left(1 \mu \mathrm{mol}\right.$ of TDIC per $\mu \mathrm{mol}$ of $\mathrm{Ca}^{2+}$ and $\mathrm{Mg}^{2+}$ ) during the incubations. All terms were then converted to mass units $\left(\mu \mathrm{gCg}^{-1} \mathrm{~d}^{-1}\right)$ after multiplying by 12 .

Since there is a large body of literature that estimates NEP, $R$ and PP using changes in the dissolved $\mathrm{O}_{2}$ content of the incubations instead of TDIC changes (e.g. Hodson and others, 2007; Anesio and others, 2009), we produced a 
further set of estimates using:

$$
\begin{gathered}
\mathrm{NEP}^{\mathrm{O}_{2}}=-\Delta \mathrm{O}_{2}{ }^{\text {light }}-1.875\left[\Delta \mathrm{SO}_{4}\right]^{\text {light }} \\
R^{\mathrm{O}_{2}}=-\Delta \mathrm{O}_{2}{ }^{\text {dark }}-1.875\left[\Delta \mathrm{SO}_{4}\right]^{\text {dark }} \\
\mathrm{PP}^{\mathrm{O}_{2}}=\left(-\Delta \mathrm{O}_{2}{ }^{\text {light }}-1.875\left[\Delta \mathrm{SO}_{4}\right]^{\text {light }}\right)-R^{\mathrm{O}_{2}} .
\end{gathered}
$$

These equations assume that the respiratory and the photosynthesis quotients are unity, such that 1 mole of $\mathrm{O}_{2}$ consumption represented 1 mole of TDIC production (and vice versa), after correcting for sulphide oxidation, $\Delta \mathrm{SO}_{4}$, the only chemical oxygen demand known in the system (Yde and others, 2008). $\Delta \mathrm{SO}_{4}$ was calculated from the batch average $\mathrm{SO}_{4}{ }^{2-}$ change following incubation. The coefficient 1.875 is the molar ratio of $\mathrm{O}_{2}$ consumption to $\mathrm{SO}_{4}{ }^{2-}$ production during sulphide oxidation:

$$
\begin{aligned}
& 4 \mathrm{FeS}_{2(\mathrm{~s})}+14 \mathrm{H}_{2} \mathrm{O}_{(\mathrm{I})}+15 \mathrm{O}_{2(\mathrm{~g})} \\
& =4 \mathrm{Fe}(\mathrm{OH})_{3(\mathrm{~s})}+8 \mathrm{SO}_{4(\mathrm{aq})}^{2-}+16 \mathrm{H}^{+}{ }_{(\mathrm{aq})} .
\end{aligned}
$$

Interestingly, carbonate dissolution is most likely to neutralize the $\mathrm{H}^{+}$ions produced on the right-hand side of Equation (8) such that a proportion of $[\Delta \mathrm{Ca}+\Delta \mathrm{Mg}]^{\text {light }}$ and $[\Delta \mathrm{Ca}+\Delta \mathrm{Mg}]^{\text {dark }}$ might be coupled to the sulphide oxidation process. However, since $\mathrm{SO}_{4}{ }^{2-}$ can also be biologically produced or derived from either acid sulphate aerosol or secondary evaporite dissolution (e.g. $\left.(\mathrm{Ca}, \mathrm{Mg}) \mathrm{SO}_{4}\right)$, estimates of this process are uncertain. Only the latter process would yield large errors in the TDIC partitioning between organic and inorganic processes (by producing $\mathrm{Ca}^{2+}$ and $\mathrm{Mg}^{2+}$ but no TDIC). However, such evaporites are unheard of on melting glacier surfaces, most likely because they are highly soluble and the glacial environment is more conducive to condensation than evaporation, at least in the case of a Svalbard glacier (e.g. Hodson and others, 2005). By contrast, sulphide oxidation has been documented on glacier surfaces, and examples include debris-mantled Himalayan glaciers (e.g. Hasnain and Thayyen, 1999). The maximum contribution of sulphide oxidation to $[\Delta \mathrm{Ca}+\Delta \mathrm{Mg}]^{\text {light }}$ and $[\Delta \mathrm{Ca}+\Delta \mathrm{Mg}]^{\text {dark }}$ production will therefore be considered later.

\section{Dissolved $\mathrm{O}_{2}$ and total dissolved inorganic carbon determinations}

Dissolved oxygen was measured using a factory-calibrated (and new) Hach luminescence-type dissolved oxygen (LDO) sensor. The measurement was usually stable within $30 \mathrm{~s}$ when measured in a shaded bottle. The coefficient of variation of field replicate measurements was $0-5 \%$ (average $0.6 \%$ ), indicating low precision errors.

TDIC was measured by analysing the headspace of an acidified aliquot of sample. Briefly, a $30 \mathrm{~mL}$ aliquot was drawn into a $60 \mathrm{~mL}$ syringe and attached to a soda-lime $\mathrm{CO}_{2}$ scrubber (hand-built using $40 \mathrm{~mL}$ of soda granules within another $60 \mathrm{~mL}$ syringe) via a Luer-lok ${ }^{\mathrm{TM}}$ three-way stopcock. A $30 \mathrm{~mL} \mathrm{CO}$-free headspace was then drawn into the sample followed by $2 \mathrm{~mL}$ of $\sim 5 \% \mathrm{HCl}$. The stopcock was then closed and the mixture agitated for $1 \mathrm{~min}$. The resultant headspace was drawn into a dry $30 \mathrm{~mL}$ syringe prior to being injected into a PP Systems EGM4 infrared $\mathrm{CO}_{2}$ gas analyser (IRGA) in three successive $10 \mathrm{~mL}$ aliquots. The IRGA was in static mode and produced stable $\mathrm{CO}_{2}$ measurements typically within $3 \mathrm{~s}$. The coefficient of variation of the three measurements indicated great stability and thus low precision errors for samples (0-3\%, average $0.3 \%$ ). Blank determinations showed greater replication errors (coefficient of variation $0-11 \%$ ) and also showed concentrations $>0$ (usually 8-21 ppmv in the headspace). By comparison, the incubations produced 200-8000 ppmv $\mathrm{CO}_{2}$ in the headspace, demonstrating great sensitivity in the method. Calibration was achieved using five $\mathrm{Na}_{2} \mathrm{CO}_{3}$ standards across the range $0-1 \mathrm{mmol}$ and treated in the same way as the samples.

\section{Cation and anion determinations}

All samples were defrosted for the first time back in the Sheffield laboratory and analysed for major ions using Dionex ICS90 units dedicated to anions and cations separately. Although discernible, neither $\mathrm{NH}_{4}{ }^{+}$nor $\mathrm{PO}_{4}{ }^{3-}$ could be quantified, which was surprising given our experience in past studies of glacial runoff. We believe that this was due to microbial processes within the snowpack and cryoconite habitats. Otherwise, $\mathrm{Ca}^{2+}, \mathrm{Mg}^{2+}, \mathrm{Na}^{+}, \mathrm{K}^{+}$, $\mathrm{Cl}^{-}, \mathrm{NO}_{3}{ }^{-}$and $\mathrm{SO}_{4}{ }^{2-}$ were determined with precision errors of $5 \%$ or less according to the analysis of reference standards in the mid-range of our calibration standards.

\section{Physical, chemical and biological characterization of cryoconite}

The dry mass of all cryoconite used was determined after oven drying at $40^{\circ} \mathrm{C}$. This cryoconite was then used to determine the physical and chemical characteristics. These included per cent organic matter (furnace at $400^{\circ} \mathrm{C}$ ) and the particle size of both the entire cryoconite aggregate and its constituent particles. The disaggregation required for the latter was achieved by boiling the cryoconite in a $30 \%$ hydrogen peroxide solution for $<1$ hour and until effervescence ceased. Comparison against Calgon-treated and sonicated duplicates showed this to be the most efficient way to disaggregate the cryoconite. Particle size analysis was then undertaken on a Horiba LA950 laser particle sizer following standard operating protocols. Sizing of the entire aggregates was achieved using the Image analysis described previously, before any dehydration and physical deterioration had occurred.

A mineralogical investigation of Longyearbreen cryoconite was also undertaken, utilizing powder X-ray diffraction (XRD) and $\mathrm{KBr}$-pellet Fourier transform infrared (FTIR) spectroscopy on oven-dried samples in the laboratory. The XRD was performed on a Siemens D500 powder diffractometer (Cu-source), with $150 \mathrm{mg}$ of finely powdered cryoconite, at angles of $10-80^{\circ}$, at $1^{\circ} \mathrm{min}^{-1}$ and with a step size of 0.02. KBr-FTIR was performed on a PerkinElmer Spectrum One, with $3 \mathrm{mg}$ of finely ground cryoconite and $150 \mathrm{mg}$ of $\mathrm{KBr}$ granules $(1: 50)$, pressed into a disc; 100 scans were sequentially recorded and averaged.

Stable-isotopic analyses of the $\delta^{13} \mathrm{C}$ and $\delta^{15} \mathrm{~N}$ of four bulk samples from the ablation area were also undertaken. Samples were desiccated, milled and analysed on a Sercon PDZ Europa 20-20 ANCA-GSL (Automatic Nitrogen and Carbon Analyser - Gas, Solids and Liquids) isotope ratio mass spectrometer. Analysis followed standard operating conditions for solid samples, with an estimated precision of $0.2 \%$ and $0.3 \%$ for $\delta^{13} \mathrm{C}$ and $\delta^{15} \mathrm{~N}$ respectively.

Larger cryoconite aggregates had a robust structure that allowed biological image analysis of bulk samples after transportation back to the UK. In the field, cryoconite material was therefore collected and immediately fixed in $2 \%$ paraformaldehyde and refrigerated. In the UK, single 

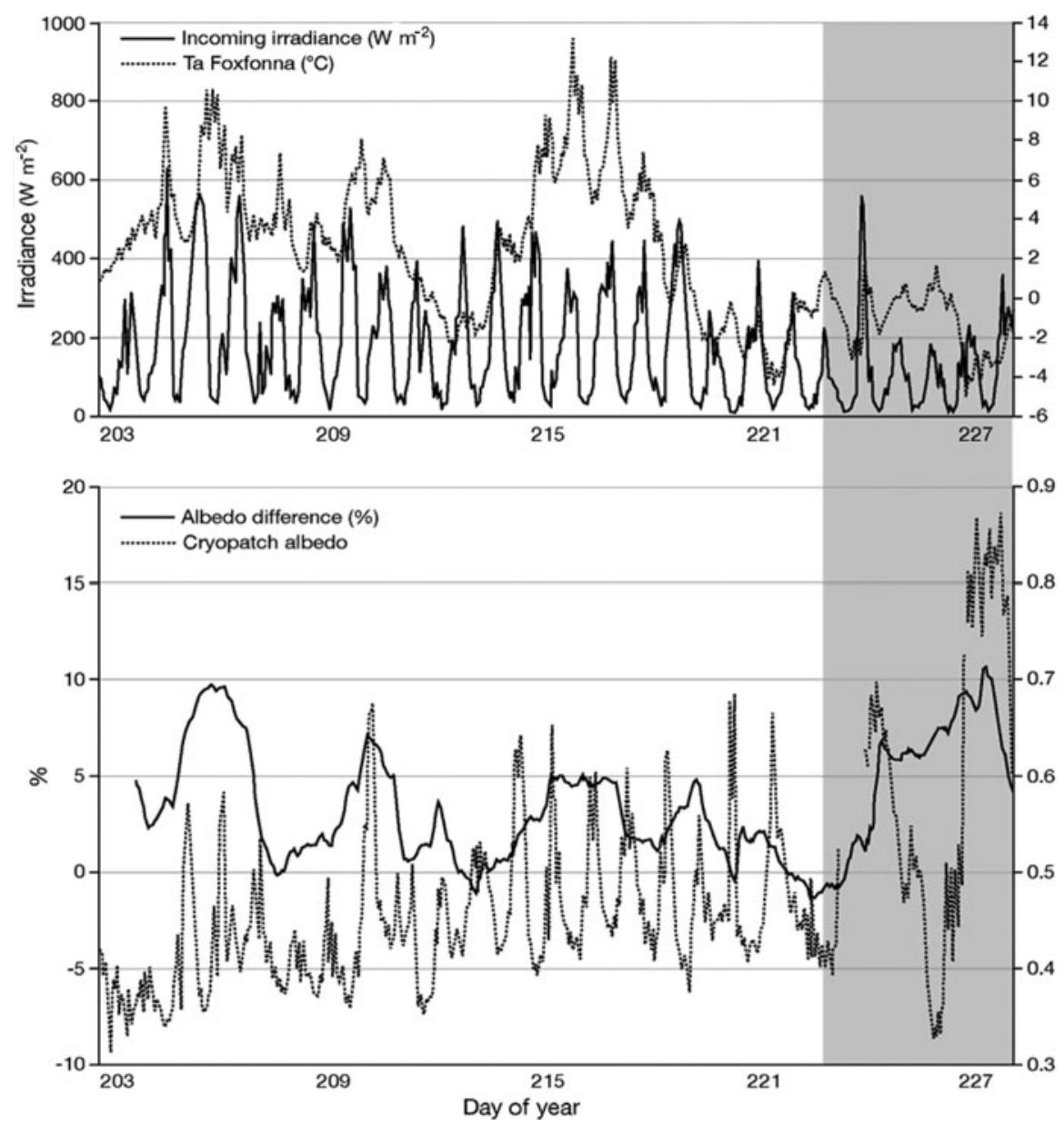

Fig. 2. Incoming shortwave irradiance at the Cryoplot, albedo at the Cryopatch and the albedo difference between the Cryopatch and Control Plot (smoothed with a 24-point running mean). Air-temperature observations are for a weather station situated $10 \mathrm{~km}$ to the east of and $\sim 400 \mathrm{~m}$ above the study site (Hodson, unpublished data). Note that the albedo values increase at night, reaching values in excess of 0.6 when ice lids form. The shaded area shows even higher albedos due to snow. Partial snowmelt caused the low albedo on DOY 225.

aggregates were mounted in OCT mounting compound and frozen at $-80^{\circ} \mathrm{C}$. The embedded aggregate was then sectioned on a Superfrost slide. Sections were allowed to dry for an hour and then covered in $1 \mathrm{~mL}$ of DAPI stain $\left(4^{\prime}, 6-\right.$ diamidino-2-phenylindole at $0.1 \mu \mathrm{g} \mathrm{mL}^{-1}$ final concentration) for $5 \mathrm{~min}$. The DAPI is a fluorescent stain which binds to the DNA of live or fixed cells and therefore allows their position to be observed on and within the aggregates when observed with a fluorescent microscope.

\section{RESULTS}

\section{Cryoplot observations}

Figure 2 shows the meteorological conditions and the Cryoconite Patch albedo throughout the observation period. The area of cryoconite cover within the camera's ROI (discussed below) influenced the albedo of the Cryoconite Patch significantly $(p<0.05)$, although it was by no means the only control since a linear regression analysis explained just $53 \%$ of the variance in albedo shown in Figure 2. One reason for the weak control was the deepening of cryoconite holes during clear-sky conditions (e.g. DOY 204-206), making the debris less 'visible' to the sun's radiation. Figure 2 also shows the smoothed difference between the Cryoconite Plot and the Control Plot albedos (positive values meaning more radiation absorption at the former). The smoothing was necessary due to noise resulting from the formation of a surface ice layer on certain nights. This reduced the albedo difference between the two patches markedly, and resulted in the strong diurnal variation in the Cryoconite Patch albedo that is observable in Figure 2. Further, the rather unexpected evolution of the Control Plot into something that resembled the Cryoconite Plot (Fig. 1) also caused the difference between the two plots to decline, at least until the snowfalls on DOY 222. Figure 2 also records a significant increase in the albedo of the Cryoconite Patch through the observation period. Two processes were behind this trend: first there was snow at the end of the monitoring period, causing the albedo values to rise sharply to $>0.6$; secondly, there was a loss of cryoconite aggregates to meltwater outflow, discussed later. The time-lapse images not influenced by snow cover therefore reveal a significant decrease in cryoconite cover from $\sim 12 \%$ to $7 \%$ prior to DOY 227 (Fig. 3).

\section{Aqueous geochemistry}

Table 1 shows summary statistics of the geochemical conditions in slush, stream waters and incubated waters, whilst Table 2a-c present Pearson's product-moment correlation matrices for these data when categorized into Stream and Slush Waters (i.e. the pre-incubation waters), Dark Incubation Waters and Light Incubation Waters. The summary statistics show few consistent differences between 
Table 1. Summary statistics of the concentrations of major ions, TDIC and dissolved oxygen in incubation waters (light and dark vessels), ice melt and slush. Units are ppm. Italicized values are the standard deviation. 'b.d.' means below detection limits

\begin{tabular}{|c|c|c|c|c|c|c|c|c|c|c|}
\hline Water type & $\mathrm{O}_{2}$ & TDIC & $\mathrm{Cl}$ & $\mathrm{SO}_{4}$ & $\mathrm{NO}_{3}$ & $\mathrm{Na}$ & $\mathrm{NH}_{4}$ & K & $M g$ & $\mathrm{Ca}$ \\
\hline \multirow[t]{2}{*}{ Slush incubated in dark } & 11.5 & 0.285 & 1.034 & 0.128 & 0.086 & 0.827 & b.d. & 0.084 & 0.128 & 0.673 \\
\hline & 0.448 & 0.079 & 0.233 & 0.013 & 0.034 & 0.142 & & 0.037 & 0.026 & 0.284 \\
\hline \multirow[t]{2}{*}{ Slush incubated in light (bottom of snow) } & 11.9 & 0.189 & 1.563 & 0.212 & 0.028 & 0.877 & b.d. & 0.114 & 0.125 & 0.478 \\
\hline & 0.189 & 0.051 & 0.293 & 0.087 & 0.026 & 0.071 & & 0.026 & 0.014 & 0.136 \\
\hline \multirow[t]{2}{*}{ Slush incubated in light (top of snow) } & 12.0 & 0.233 & 1.237 & 0.146 & 0.066 & 0.841 & b.d. & 0.097 & 0.139 & 0.404 \\
\hline & 0.314 & 0.076 & 0.278 & 0.045 & 0.017 & 0.178 & & 0.081 & 0.041 & 0.098 \\
\hline \multirow[t]{2}{*}{ Slush and cryoconite incubated in dark } & 7.00 & 2.134 & 2.385 & 0.335 & 0.151 & 1.903 & 0.002 & 0.248 & 0.667 & 1.547 \\
\hline & 0.731 & 0.260 & 0.360 & 0.022 & 0.058 & 0.176 & 0.004 & 0.033 & 0.047 & 0.093 \\
\hline \multirow{2}{*}{$\begin{array}{l}\text { Slush and cryoconite incubated in light } \\
\text { (bottom of snow) }\end{array}$} & 7.06 & 0.968 & 2.530 & 0.326 & 0.031 & 1.229 & 0.027 & 0.266 & 0.394 & 0.783 \\
\hline & 0.240 & 0.092 & 0.753 & 0.139 & 0.004 & 0.365 & 0.013 & 0.110 & 0.247 & 0.201 \\
\hline \multirow{2}{*}{$\begin{array}{l}\text { Slush and cryoconite incubated in light } \\
\text { (top of snow) }\end{array}$} & 11.1 & 0.357 & 1.349 & 0.198 & 0.047 & 0.817 & b.d. & 0.085 & 0.343 & 0.826 \\
\hline & 0.693 & 0.258 & 0.094 & 0.005 & 0.011 & 0.006 & & 0.011 & 0.012 & 0.043 \\
\hline \multirow{2}{*}{$\begin{array}{l}\text { Ice melt and cryoconite incubated in light } \\
\text { (glacier surface) }\end{array}$} & 10.91 & 0.916 & 2.625 & 0.840 & 0.078 & 1.912 & b.d. & 0.389 & 0.287 & 1.118 \\
\hline & 1.36 & 0.694 & 1.388 & 0.154 & 0.058 & 0.474 & & 1.051 & 0.112 & 0.180 \\
\hline \multirow{4}{*}{$\begin{array}{l}\text { Ice melt and cryoconite incubated in dark } \\
\text { (glacier surface) } \\
\text { Ice melt and cryoconite incubated in dark } \\
\text { (incubator at } 4^{\circ} \mathrm{C} \text { ) }\end{array}$} & 8.38 & 2.606 & 1.518 & 0.759 & 0.122 & 1.606 & b.d. & 0.127 & 0.288 & 1.358 \\
\hline & 0.581 & 0.312 & 0.524 & 0.062 & 0.071 & 0.256 & & 0.047 & 0.110 & 0.169 \\
\hline & 1.20 & 9.066 & 4.367 & 1.156 & 0.120 & 3.178 & 0.017 & 0.677 & 1.166 & 2.577 \\
\hline & 0.374 & 1.066 & 0.592 & 0.035 & 0.059 & 0.394 & 0.034 & 0.104 & 0.202 & 0.435 \\
\hline \multirow[t]{2}{*}{ Slush incubation waters } & 12.8 & 0.171 & 0.656 & 0.095 & 0.044 & 0.654 & b.d. & 0.037 & 0.074 & 0.358 \\
\hline & 0.247 & 0.016 & 0.109 & 0.017 & 0.014 & 0.185 & & 0.026 & 0.004 & 0.079 \\
\hline \multirow[t]{2}{*}{ Ice-melt incubation waters } & 12.0 & 0.647 & 1.808 & 0.942 & 0.103 & 1.486 & b.d. & 0.188 & 0.227 & 0.909 \\
\hline & 0.363 & 0.491 & 0.380 & 0.607 & 0.092 & 0.361 & & 0.062 & 0.091 & 0.359 \\
\hline
\end{tabular}

Table 2. Correlation matrices for (a) all light incubations, (b) all dark incubations and (c) all slush and stream water samples. n/a means not available

$\begin{array}{lllllllll}\mathrm{O}_{2} & \mathrm{TDIC} & \mathrm{Cl} & \mathrm{SO}_{4} & \mathrm{NO}_{3} & \mathrm{Na} & \mathrm{NH}_{4} & \mathrm{~K} & \mathrm{Mg}\end{array}$

(a) Light Incubation Waters

\begin{tabular}{|c|c|c|c|c|c|c|c|c|c|}
\hline TDIC & -0.77 & 1 & & & & & & & \\
\hline $\mathrm{Cl}$ & -0.07 & 0.43 & 1 & & & & & & \\
\hline $\mathrm{SO}_{4}$ & -0.16 & 0.56 & 0.62 & 1 & & & & & \\
\hline $\mathrm{NO}_{3}$ & -0.25 & 0.27 & 0.30 & 0.34 & 1 & & & & \\
\hline $\mathrm{Na}$ & -0.15 & 0.54 & 0.72 & 0.92 & 0.29 & 1 & & & \\
\hline $\mathrm{NH}_{4}$ & $\mathrm{n} / \mathrm{a}$ & $\mathrm{n} / \mathrm{a}$ & $\mathrm{n} / \mathrm{a}$ & $\mathrm{n} / \mathrm{a}$ & $\mathrm{n} / \mathrm{a}$ & $\mathrm{n} / \mathrm{a}$ & 1 & & \\
\hline K & -0.14 & 0.30 & 0.77 & 0.18 & 0.43 & 0.19 & $\mathrm{n} / \mathrm{a}$ & 1 & \\
\hline $\mathrm{Mg}$ & -0.33 & 0.54 & 0.52 & 0.60 & 0.02 & 0.67 & $\mathrm{n} / \mathrm{a}$ & 0.13 & 1 \\
\hline $\mathrm{Ca}$ & -0.51 & 0.82 & 0.66 & 0.81 & 0.40 & 0.76 & $\mathrm{n} / \mathrm{a}$ & 0.44 & 0.69 \\
\hline \multicolumn{10}{|c|}{ (b) Dark Incubation Waters } \\
\hline TDIC & -0.94 & 1 & & & & & & & \\
\hline $\mathrm{Cl}$ & -0.78 & 0.70 & 1 & & & & & & \\
\hline $\mathrm{SO}_{4}$ & -0.82 & 0.86 & 0.62 & 1 & & & & & \\
\hline $\mathrm{NO}_{3}$ & -0.29 & 0.37 & 0.01 & 0.29 & 1 & & & & \\
\hline $\mathrm{Na}$ & -0.93 & 0.90 & 0.82 & 0.80 & 0.35 & 1 & & & \\
\hline $\mathrm{NH}_{4}$ & 0.03 & -0.08 & 0.43 & 0.00 & -0.24 & 0.04 & 1 & & \\
\hline $\mathrm{K}$ & -0.68 & 0.62 & 0.79 & 0.54 & 0.01 & 0.64 & 0.16 & 1 & \\
\hline $\mathrm{Mg}$ & -0.87 & 0.80 & 0.87 & 0.61 & 0.22 & 0.91 & 0.17 & 0.60 & 1 \\
\hline $\mathrm{Ca}$ & -0.87 & 0.86 & 0.68 & 0.79 & 0.55 & 0.90 & 0.07 & 0.60 & 0.81 \\
\hline \multicolumn{10}{|c|}{ (c) Stream and Slush Waters } \\
\hline TDIC & 0.02 & 1 & & & & & & & \\
\hline $\mathrm{Cl}$ & 0.13 & -0.18 & 1 & & & & & & \\
\hline $\mathrm{SO}_{4}$ & 0.05 & 0.88 & 0.34 & 1 & & & & & \\
\hline $\mathrm{NO}_{3}$ & 0.09 & 0.35 & 0.72 & 0.59 & 1 & & & & \\
\hline $\mathrm{Na}$ & 0.13 & 0.13 & 0.94 & 0.59 & 0.84 & 1 & & & \\
\hline $\mathrm{NH}_{4}$ & $\mathrm{n} / \mathrm{a}$ & $\mathrm{n} / \mathrm{a}$ & $\mathrm{n} / \mathrm{a}$ & $\mathrm{n} / \mathrm{a}$ & $\mathrm{n} / \mathrm{a}$ & $\mathrm{n} / \mathrm{a}$ & 1 & & \\
\hline K & -0.17 & 0.05 & 0.92 & 0.51 & 0.74 & 0.93 & $\mathrm{n} / \mathrm{a}$ & 1 & \\
\hline $\mathrm{Mg}$ & 0.37 & 0.82 & 0.41 & 0.97 & 0.62 & 0.63 & $\mathrm{n} / \mathrm{a}$ & 0.49 & 1 \\
\hline $\mathrm{Ca}$ & 0.02 & 0.89 & 0.26 & 0.98 & 0.49 & 0.52 & $\mathrm{n} / \mathrm{a}$ & 0.44 & 0.913 \\
\hline
\end{tabular}




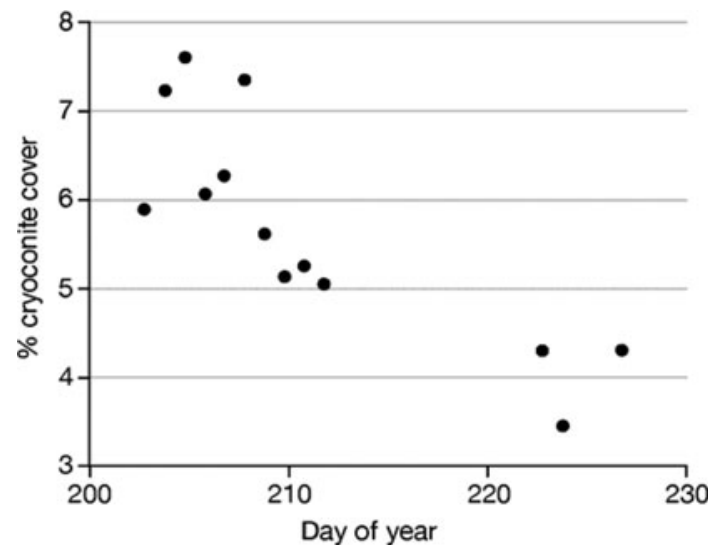

Fig. 3. Decreasing cryoconite in the time-lapse images collected from the Cryoplot. Images are from $1900 \mathrm{~h}$ because this was the earliest time that the entire Cryoplot became shaded, yielding images that were easier to process prior to surface freezing. The gap in the series is due to camera malfunction between DOY 211 and 222.

these categories, except for (1) elevated $\mathrm{Ca}^{2+}$ and $\mathrm{Mg}^{2+}$ in any incubation that involved cryoconite and (2) the expected differences (high TDIC and low $\mathrm{O}_{2}$ ) in the dark incubations relative to the initial solutions (i.e. slush and stream waters). However, the correlation matrices shown in Table 2a-c help identify two important inorganic solute sources to the system under study: marine aerosol and dissolution of debris. The marine aerosol solute supply is clear in the correlation matrix for the Stream and Slush Waters, where strong, positive correlations between $\mathrm{Na}^{+}$, $\mathrm{Cl}^{-}, \mathrm{K}^{+}$and $\mathrm{NO}_{3}^{-}$are evident. These solutes are also strongly correlated in both the Light and Dark Incubation
Waters, with the exception of $\mathrm{NO}_{3}{ }^{-}$, which is most likely decoupled from $\mathrm{Na}^{+}, \mathrm{Cl}^{-}$and $\mathrm{K}^{+}$by biological processes. The influence of dissolution of solute from debris is such that samples display enrichment of $\mathrm{Ca}^{2+}$ and $\mathrm{Mg}^{2+}$ in the order Slush < Streams < Light Incubation Waters < Dark Incubation Waters. These solutes are strongly diagnostic of carbonate weathering, which is described in the catchment by Yde and others (2008). Otherwise, TDIC demonstrates a clear microbial influence from its strong, negative association with $\mathrm{O}_{2}$, which is most pronounced in the Dark Incubation Waters.

\section{Aggregate geochemistry}

Figure 4 shows a typical XRD result for our analyses of four cryoconite powders. The strongest peaks correspond well to the International Centre for Diffraction Data (ICDD) file 461045 , indicating the presence and relative abundance of quartz. The presence of carbonate minerals is also indicated primarily as dolomite. The majority of the remaining minor peaks are indicative of kaolinite-type clays, muscovite, biotite and orthoclase feldspar (Cullity 1978; Ruffell and Wiltshire 2004).

The $\mathrm{KBr}$-FTIR results in Figure 5 reveal absorption peaks characteristic of the presence of silicate minerals. The two peaks at $\sim 3600 \mathrm{~cm}^{-1}$ ((a) in Fig. 5) can be ascribed to the stretching vibrations of inner hydroxyl groups situated between the tetrahedral and octahedral sheets of kaolinitetype clays (Madejová, 2003). The broad hump at (b) is indicative of basic (free) hydroxyl groups, especially when the peak at $\sim 1640 \mathrm{~cm}^{-1}$ is present. The absorbance at (c), $\sim 1450 \mathrm{~cm}^{-1}$, is attributed to dolomite (A. Matteson and M.A. Herron, http://www.scaweb.org/assets/papers/ 1993_papers/1-SCA1993-08.pdf). The absorbance pattern between $1200 \mathrm{~cm}^{-1}$ and $450 \mathrm{~cm}^{-1}(\mathrm{~d}-\mathrm{f})$ is more complex in

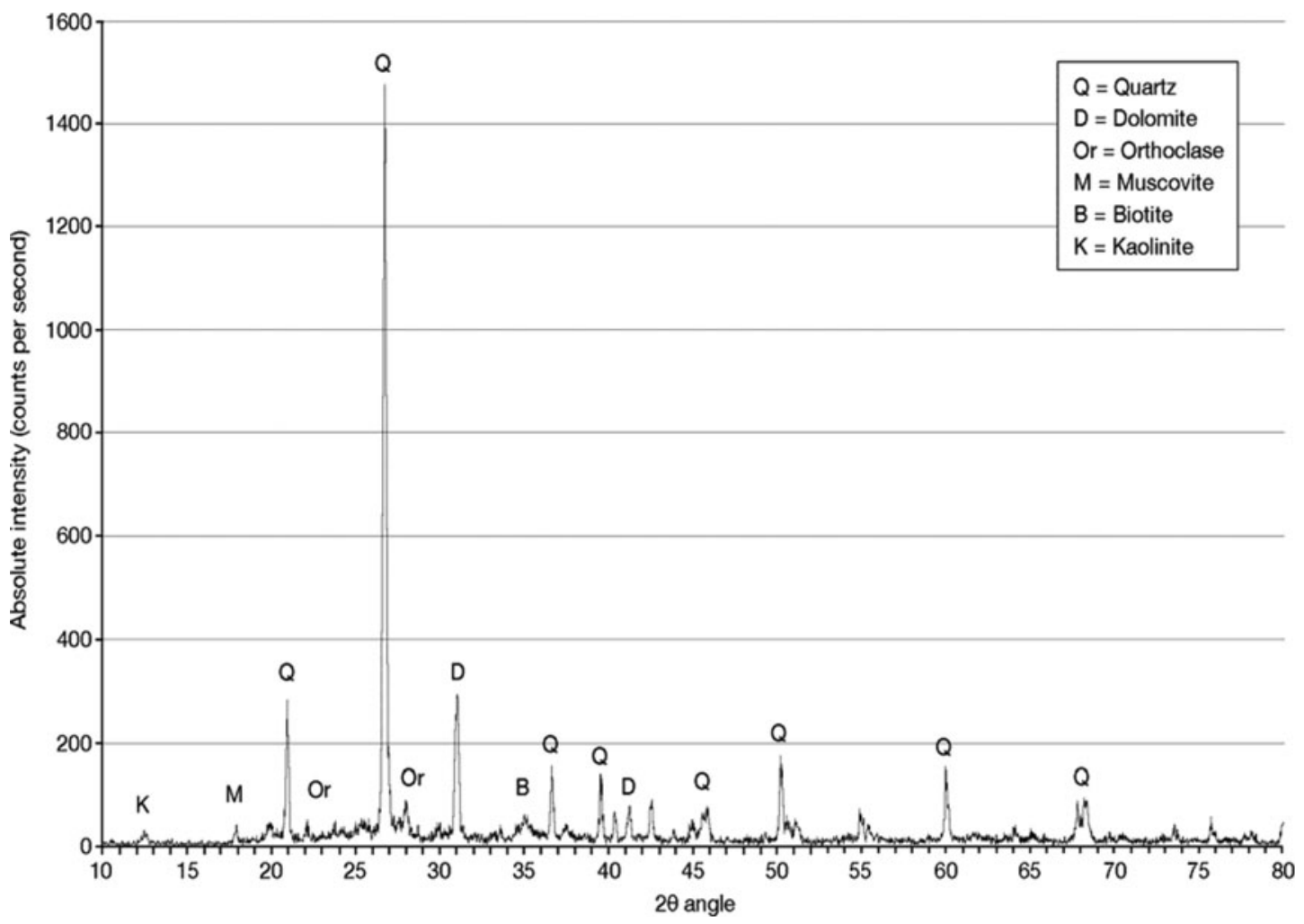

Fig. 4. A typical powder XRD analysis showing the dominance of silicate and dolomite minerals in the cryoconite. 


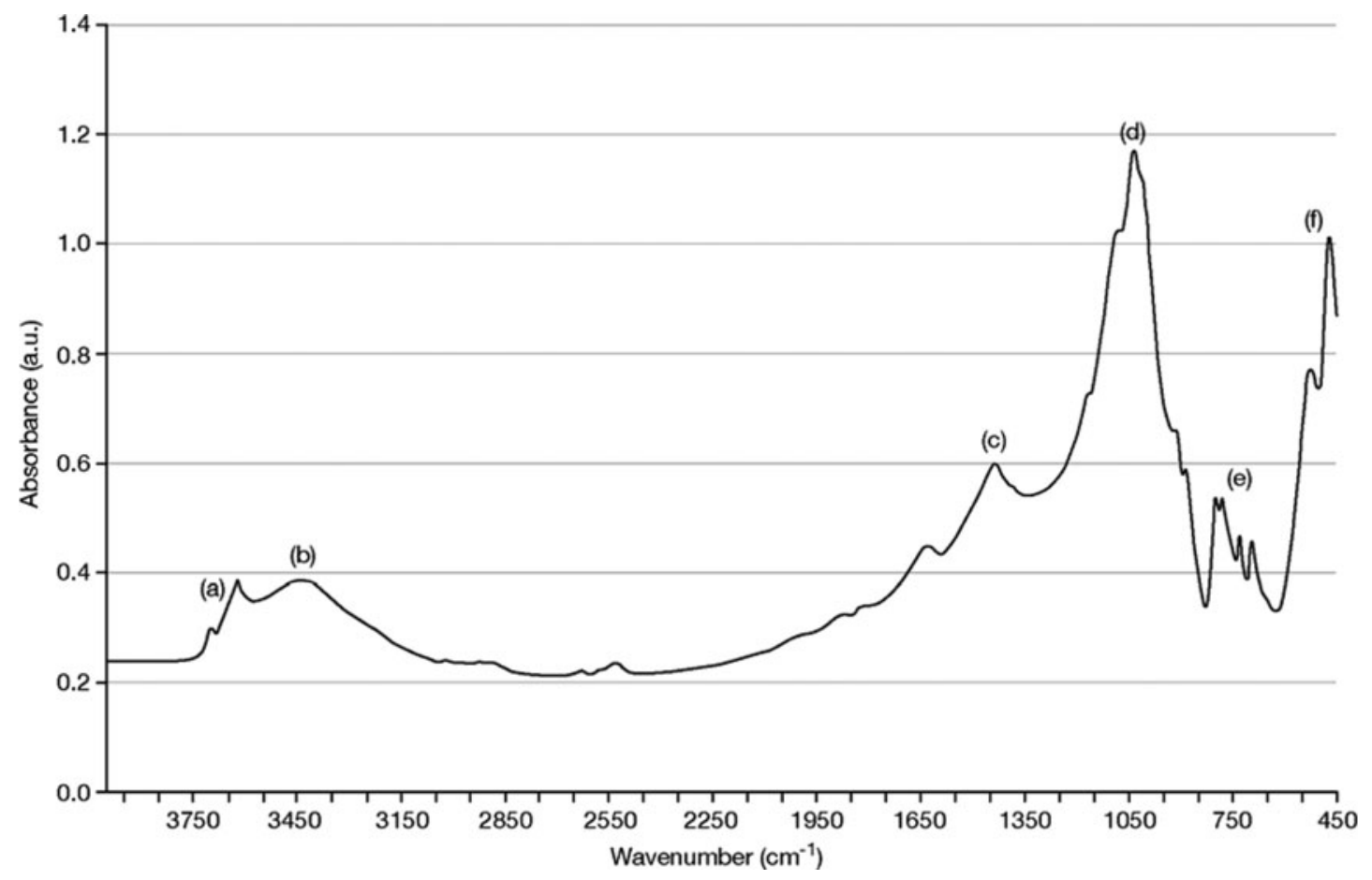

Fig. 5. Typical KBr-FTIR results for a single cryoconite sample, also showing absorption peaks characteristic of the presence of silicate minerals. Peaks $(a-f)$ are described in the text.

nature, but indicative of both quartz (strong peak at $\sim 1050 \mathrm{~cm}^{-1}$; double peak at $\sim 800 \mathrm{~cm}^{-1}$; two peaks between 500 and $450 \mathrm{~cm}^{-1}$ ) and clay minerals, in particular illite and smectite (shoulders on strong quartz peak; twin peaks at $\sim 700 \mathrm{~cm}^{-1}$ (A. Matteson and M.A. Herron, http://www. scaweb.org/assets/papers/1993_papers/1-SCA1993-08.pdf; Madejová, 2003). Therefore, the mineralogy of the Longyearbreen cryoconite is most likely dominated by quartz, orthoclase feldspar, muscovite, biotite and dolomite. The silicate alteration products appear to be dominated by kaolinite, illite and smectite, and their presence is probably linked more to the physical weathering of shale than in situ silicate weathering (Yde and others, 2008).

\section{Community NEP, PP and $R$}

Figure 6 shows estimates of PP ${ }^{\text {TDIC }}, R^{\text {TDIC }}$ and NEP ${ }^{\text {TDIC }}$ for the slush incubations undertaken both with and without cryoconite. As has been found elsewhere (Hodson and others, 2007; Anesio and others, 2009), the slush-only incubations indicated rates that were markedly lower (i.e. average PP up to $60 \mu \mathrm{gCL}^{-1} \mathrm{~d}^{-1}$ ) than when slush was inoculated with cryoconite aggregates (i.e. average $>500 \mu \mathrm{gC} \mathrm{L}^{-1} \mathrm{~d}^{-1}$ ). In fact, with the exception of pit 1 , the slush-only incubations were not significantly different from zero.

Figure 7 and Table 3 present the cryoconite incubation data normalized for unit dry mass estimated using changes in both TDIC and $\mathrm{O}_{2}$ (Table 3 only). The data show a small

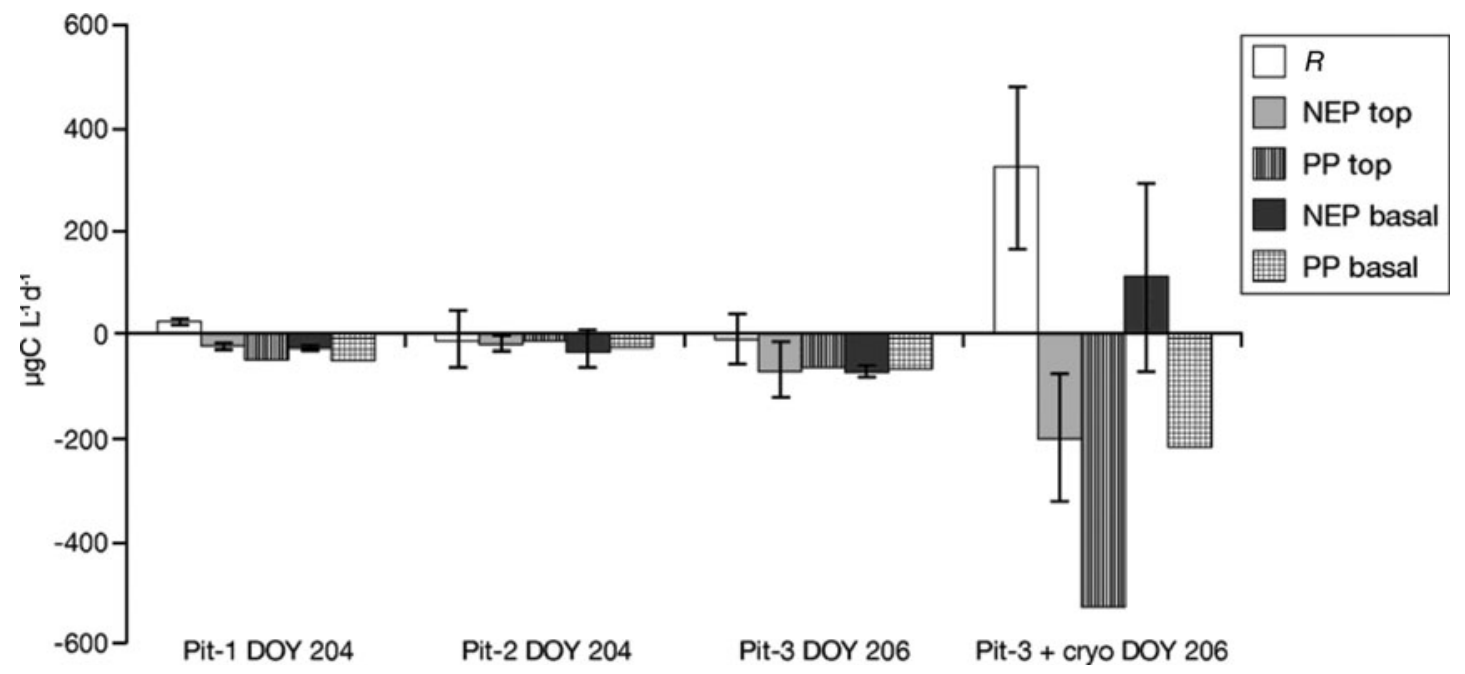

Fig. 6. Community respiration, $R^{\mathrm{TDIC}}$, net ecosystem production, $\mathrm{NEP}{ }^{\mathrm{TDIC}}$, and primary production, $\mathrm{PP}^{\mathrm{TDIC}}$, for slush incubations at pits $1-3$. 'Pit-3 + cryo' denotes inoculation of slush with $\sim 0.125 \mathrm{~g} \mathrm{~cm}^{-2}$ of cryoconite. 'Top' and 'basal' indicate the position of the light incubations within the snowpack (the latter being $50 \mathrm{~cm}$ below the surface). Error bars represent one standard deviation (where applicable). Negative values are used for $\mathrm{CO}_{2}$ fixation into the system during primary production, whilst positive values mean production during respiration. 


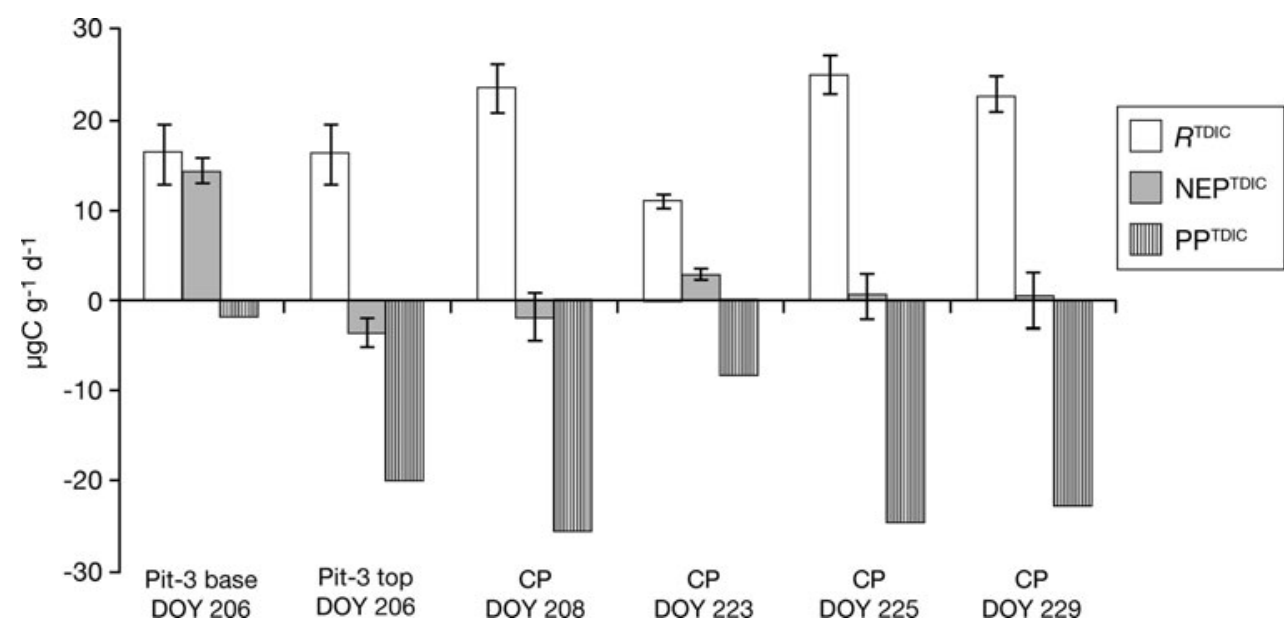

Fig. 7. Average community respiration, $R^{\mathrm{TDIC}}$, net ecosystem production, NEP ${ }^{\mathrm{TDIC}}$, and primary production, PP ${ }^{\mathrm{TDIC}}$, for cryoconite incubations at pit 3 (base and surface; note negligible $\mathrm{PP}^{\mathrm{TDIC}}$ at the former) and the Cryoplot. Error bars represent one standard deviation

excess of respiration over primary production, although the system is almost balanced according to the TDIC data (such that $\mathrm{PP}^{\mathrm{TDIC}}$ is $\sim 0.9$ times $R^{\mathrm{TDIC}}$ ). In contrast, while average $R^{\mathrm{O}_{2}}$ is almost identical to $R^{\mathrm{TDIC}}$, the $\mathrm{PP}^{\mathrm{O}_{2}}$ estimates are low, so that $R^{\mathrm{O}_{2}}$ exceeds $\mathrm{PP}^{\mathrm{O}_{2}}$ by a factor of 1.7. We believe that this reflects the saturation of $\mathrm{O}_{2}$ in the light incubations, since bubble formation on the inside of the flasks was observed and it was not possible to include these gases in the analysis. Therefore, we assume that $\mathrm{PPO}_{2}$ was underestimated due to this problem, and only the NEP, PP and $R$ results based upon TDIC are discussed hereafter.

\section{Cryoconite aggregate characterizations}

The $\mathrm{C} / \mathrm{N}$ mass ratios $(13 \pm 1)$ and the $\delta^{13} \mathrm{C}$ and $\delta^{15} \mathrm{~N}$ results (versus PDB and air standards respectively) are shown in Table 4. The $\delta^{13} \mathrm{C}$ and $\delta^{15} \mathrm{~N}$ values are lower than the values reported for ice-shelf microbial mats on Ellesmere Island, Canada (average $\delta^{13} \mathrm{C}$ and $\delta^{15} \mathrm{~N}$ of $-18.95 \pm 0.5 \%$ and $-0.60 \pm 0.35 \%$ respectively; Mueller, 2005). Otherwise, they are similar to Greenland cryoconite $\left(\delta^{13} \mathrm{C}-23.7 \pm 2.2 \%\right.$ and $\delta^{15} \mathrm{~N}-9.3 \pm 3.3 \%$ ) and cryoconite from midtre Lovénbreen and Vestfonna in Svalbard $\left(\delta^{13} \mathrm{C} 25.0 \pm 0.64 \%\right.$ and $\delta^{15} \mathrm{~N}-9.2 \pm 0.4 \%$ ) (Cameron, unpublished data). The reasons for higher $\delta^{15} \mathrm{~N}$ values at Longyearbreen compared to the other Svalbard and Greenland sites are unclear, although as indicated by their larger standard deviations, greater values can also be expected on occasion at these other sites.

The size distribution of the aggregates' constituent particles reported in Table 4 shows that they were composed of fine silt (median 11.7-14.7 $\mu \mathrm{m}$; mean 22.3-25.4 $\mu \mathrm{m}$; mode $10.8-12.4 \mu \mathrm{m})$ that is characteristic of aeolian sediments (Gale and Hoare, 1991). The particle sizes of the entire aggregates were far greater (range 2.57-39.21 mm; mean $8.92 \pm 6.93 \mathrm{~mm}$; median $6.74 \mathrm{~mm}$ ), and thus unlikely to be mobilized by aeolian processes. Figure $8 \mathrm{a}$ and $\mathrm{b}$ show that these larger aggregate particles also displayed internal layering when imaged under a bright-field microscope. The layers appear to identify different sediment sources being incorporated into the grain, rather than any redox-type change within them (Hodson and others, 2008).

When the DAPI-stained granules were then observed under an ultraviolet (UV) microscope, it could also be seen that woven around the granule (as if to bind it together) were numerous filamentous microorganisms. When sectioned into $50 \mu \mathrm{m}$ sections, the same pattern was revealed, wherein filamentous cyanobacteria were restricted to the outer circumference of the granule (Fig. $8 \mathrm{~d}$ and e) but not its interior. Toward the centre (not shown), isolated specks of fluorescence were occasionally seen and it was difficult to interpret whether this was the result of DNA fluorescing within cellular material, nonspecific stain adherence or material within the granule that was autofluorescing.

Table 3. Average ( \pm standard deviation, where relevant) measures of respiration, $R$, net ecosystem production, NEP, and primary production, $\mathrm{PP}$, for cryoconite incubations conducted at the top and the base of pit 3 (P3) and at the cryoplot (CP). The superscripts 'TDIC' and ' ${ }_{2}{ }^{\prime}$ denote the use of carbon and oxygen changes respectively. Units are $\mu \mathrm{gCg}^{-1} \mathrm{~d}^{-1}$. Negative values are used for carbon fixation into the system during primary production, whilst positive values mean production during respiration

\begin{tabular}{|c|c|c|c|c|c|c|c|}
\hline Date & Location & $R^{\mathrm{O}_{2}}$ & $R^{\mathrm{TDIC}}$ & $\mathrm{NEP}^{\mathrm{O}_{2}}$ & NEP ${ }^{\text {TDIC }}$ & $\mathrm{PP}^{\mathrm{O}_{2}}$ & $\mathrm{PP}^{\mathrm{TDIC}}$ \\
\hline 24 Jul 2008 & P3 top & $26.9 \pm 5.1$ & $16.3 \pm 3.9$ & $13.9 \pm 5.0$ & $-3.83 \pm 6.1$ & -13.0 & -20.2 \\
\hline 24 Jul 2008 & P3 base & $26.9 \pm 5.1$ & $16.3 \pm 3.9$ & $25.2 \pm 2.7$ & $14.2 \pm 4.5$ & -1.67 & -2.09 \\
\hline 26 July 2008 & CP DOY 208 & $12.1 \pm 1.6$ & $23.6 \pm 2.4$ & $-6.21 \pm 3.9$ & $-2.13 \pm 1.7$ & -18.4 & -25.7 \\
\hline 10 Aug 2008 & CP DOY 223 & $9.54 \pm 0.61$ & $11.0 \pm 0.35$ & $4.03 \pm .2 .3$ & $2.72 \pm 1.8$ & -5.51 & -8.31 \\
\hline 12 Aug 2008 & CP DOY 225 & $18.2 \pm 6.8$ & $25.1 \pm 2.9$ & $2.27 \pm 2.5$ & $0.78 \pm 1.4$ & -15.91 & -24.4 \\
\hline 16 Aug 2008 & CP DOY 229 & $14.7 \pm 3.6$ & $22.9 \pm 2.7$ & $4.10 \pm 3.8$ & $0.38 \pm 1.5$ & -10.6 & -22.5 \\
\hline Average & All & $18.1 \pm 7.40$ & $19.2 \pm 5.50$ & $7.21 \pm 10.9$ & $2.03 \pm 6.41$ & $-10.9 \pm 6.3$ & $-17.2 \pm 9.7$ \\
\hline
\end{tabular}



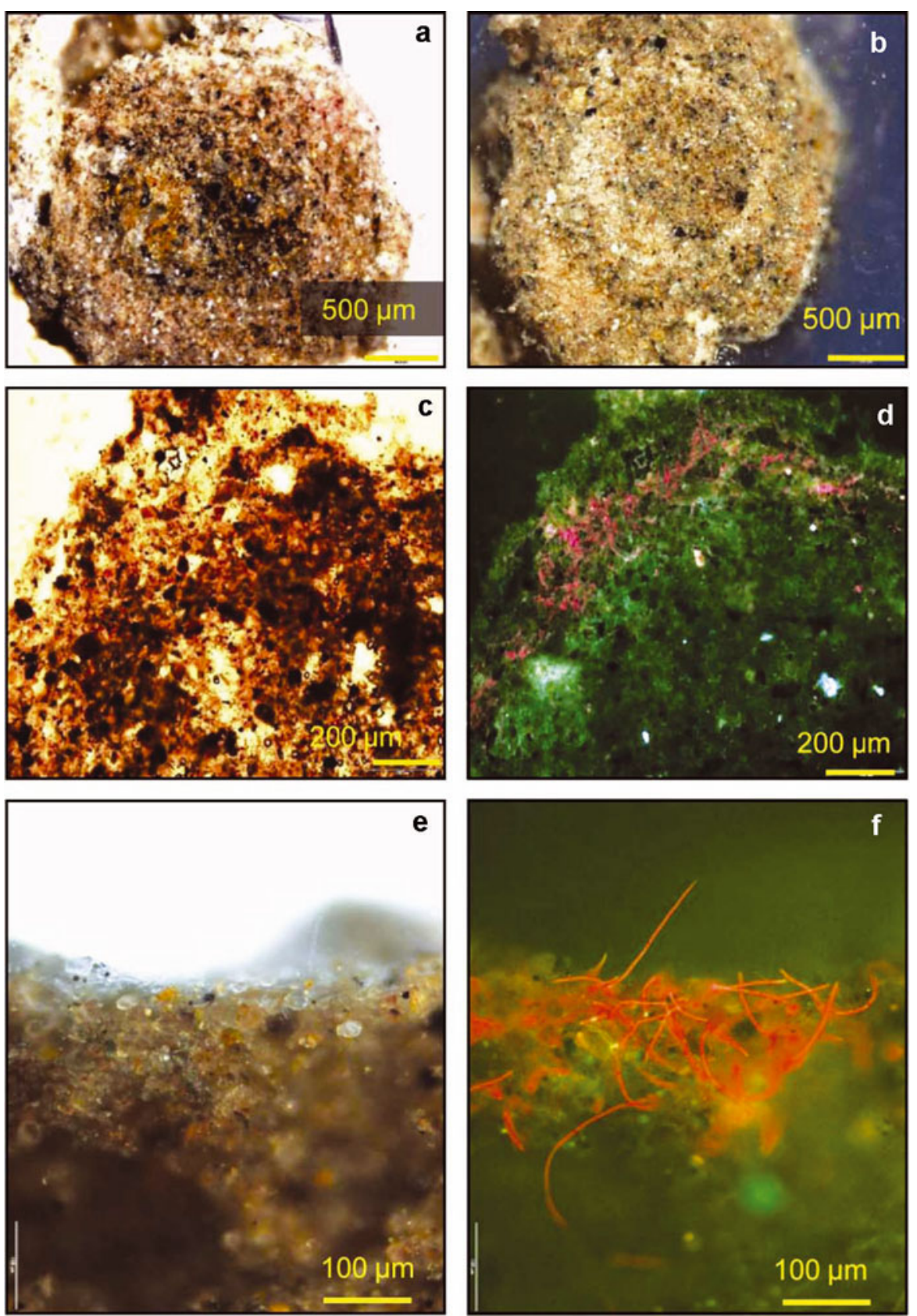

Fig. 8. Images derived from the microscopy of cryoconite aggregates under bright-field (a, b, c, e) and UV (d, f) light. Images (a) and (b) are different aggregate cut in half, showing the weak internal structure. (c) and (d) are the same thin section, with the location of the cyanobacteria indicated in pink/red when illuminated by UV light. (e) and (f) are close-up views of the edge of another thin section, again under bright-field and UV light respectively.

Table 4. Physical and chemical characteristics of cryoconite aggregates. $\% \mathrm{C}$ and $\% \mathrm{~N}$ are the mass percentages of carbon and nitrogen from the mass spectrometer

\begin{tabular}{lccr}
\hline & Mean & Std dev. & $n$ \\
\hline \% organic & 8.00 & 4.49 & 33 \\
$\% \mathrm{C}$ & 2.03 & 0.53 & 4 \\
$\delta^{13} \mathrm{C}$ & -24.6 & 1.03 & 4 \\
$\% \mathrm{~N}$ & 0.16 & 0.03 & 4 \\
$\delta^{15} \mathrm{~N}$ & -3.97 & 1.34 & 4 \\
$\mathrm{C} / \mathrm{N}$ & 12.98 & 1.12 & 4 \\
Aggregate size $(\mathrm{mm})$ & 8.92 & 6.93 & 90 \\
Particle size $(\mu \mathrm{m})$ & $22.3-25.4$ & $29.4-35.7$ & 8 \\
\end{tabular}

\section{DISCUSSION}

The formation, persistence and impacts of the cryoconite dispersed across the surface of Longyearbreen and other glaciers will remain unclear until the life cycle of these aggregates is better understood. The following discussion therefore addresses this uncertainty by integrating observations on the carbon balance, structure and mobility of cryoconite aggregates.

\section{Cryoconite carbon balance I: chemical weathering}

Since cryoconite aggregates offer micro-sites of extended rock-water interaction, their role in chemical weathering may be critical in the acquisition of nutrients and alkalinity by otherwise dilute meltwaters. The stoichiometry of 
Table 5. Primary production and respiration rates for a range of cryoconite samples

Activity $\quad$ Method (source)
$\mu \mathrm{gC} \mathrm{g} \mathrm{g}^{-1} \mathrm{~d}^{-1}$

Primary production (water and debris) Longyearbreen

Greenland ice sheet (southwest)

East Antarctic ice sheet (Vestfold Hills)

$17.2 \pm 9.7(2.09-25.7)$

$18.7 \pm 10.1(4.7-28.7)$

$2.10 \pm 1.5(0.21-4.82)$

$19.2 \pm 5.5(11.0-25.1)$

$20.9 \pm 8.2(12.2-29.6)$

$1.86 \pm 1.51(0.40-4.54)$
IRGA, light and dark incubations (this study) IRGA, light and dark incubations (Hodson, unpublished data) IRGA, light and dark incubations (Hodson, unpublished data)

IRGA, light and dark incubations (this study) IRGA, light and dark incubations (Hodson, unpublished data) IRGA, light and dark incubations (Hodson, unpublished data)
Greenland ice sheet (southwest)

East Antarctic ice sheet (Vestfold Hills)
Activity

$\mu g \mathrm{CL}^{-1} \mathrm{~d}^{-1}$
Method (source)
Primary production (water)

Midtre Lovénbreen

Austre Brøggerbreen

Vestre Brøggerbreen

Frøya Glacier

Longyearbreen slush

Community respiration (water)

Austre Brøggerbreen

Stubacher Sonnblickkees

Longyearbreen slush
$79.8 \pm 75.9(5.38-234)$
$87.5 \pm 56.0(24.8-158)$
$94.6 \pm 58.0(41.9-190)$
$53.5 \pm 59.7(7.97-183)$
$37.5 \pm 26.9(-7.66-60.0)$

$72.9 \pm 29.8$

$86.7 \pm 17.9$

$3.69 \pm 16.9(-7.35-23.1)$
$\mathrm{H}^{14} \mathrm{CO}_{3}$ incorporation, light incubations (Anesio and others, 2009) $\mathrm{H}^{14} \mathrm{CO}_{3}$ incorporation, light incubations (Anesio and others, 2009) $\mathrm{H}^{14} \mathrm{CO}_{3}$ incorporation, light incubations (Anesio and others, 2009) $\mathrm{H}^{14} \mathrm{CO}_{3}$ incorporation, light incubations (Anesio and others, 2009) IRGA, light and dark incubations (this study)

$\mathrm{O}_{2}$ change, respiratory quotient $=1$ (Anesio and others, 2009)

$\mathrm{O}_{2}$ change, respiratory quotient $=1$ (Anesio and others, 2009) IRGA, light and dark incubations (this study)
Equations (1-4) can therefore be used to place some massbalance constraints upon the relative importance of inorganic versus biological processes during the incubations. For example, $[\Delta \mathrm{Ca}+\Delta \mathrm{Mg}]^{\text {dark }}$ changes suggest that the total mineral-derived TDIC represented $14.3 \pm 12.1 \%$ of the total TDIC produced during dark incubation. Of this mineral-derived TDIC, $14.7 \pm 14.2 \%$ could be attributable to sulphide oxidation, with the rest most likely achieved by carbonate hydrolysis and acid hydrolysis reactions. Therefore TDIC and $\mathrm{O}_{2}$ produced by sulphide oxidation in cryoconite is best described as noise in the strong signal produced by ecosystem productivity and, to a far lesser extent, simple carbonate dissolution. The latter is certainly significant enough to require quantification, especially in the (more 'natural') light incubations. In these cases, mineral-derived TDIC was far more variable and represented $1-65 \%$ (average $30.0 \%$ ) of the total TDIC produced. Thus chemical weathering exerts a significant and variable impact on the export of base cations from the surface of this glacier, which is unsurprising given the likelihood that carbonate dusts are an integral component of the aggregate structure (Fig. 4).

Given the above processes, it is interesting to consider whether cryoconite is an important biocatalyst for weathering reactions upon the glacier surface (e.g. through the production of organic acids or carbonic acid following respiration of $\mathrm{CO}_{2}$ ). However, incorporation of reactive mineral phases into a cryoconite aggregate would in fact reduce the weathering rate by minimizing contact with dilute meltwater and enabling more saturated pore waters to evolve in the aggregate interior. Biogenic carbonates (and silicates) testify to net mineral precipitation in cyanobacterial mats upon the Ross Ice Shelf, Antarctica (de los Rios and others, 2004), so a similar process might occur in larger cryoconite aggregates if dissolution products are not flushed from chemical weathering environments by melt. More studies of the internal chemistry of the aggregates are therefore required before the role of cryoconite in supraglacial weathering processes can be defined.

\section{Cryoconite carbon balance II: ecosystem production}

The rates of primary production and respiration are likely to be important controls upon aggregate formation and size due to biomass change. They will also dominate ecosystem impact upon atmospheric $\mathrm{CO}_{2}$ on account of the modest chemical weathering rates recorded. The data presented in Figure 7 clearly show that these processes are active, producing carbon fluxes that are not unlike other aquatic ecosystems (including glaciers) described in Anesio and others' (2009) global synthesis (Table 5). However, respiration is far more important in the present study, and sometimes appears to more than account for the carbon fixed via photosynthesis. There is also a strong correlation between $\mathrm{PP}^{\mathrm{TDIC}}$ and $R^{\mathrm{TDIC}}\left(r^{2}=0.87\right.$; linear regression), which might reflect a tight coupling between the two processes. Such a coupling is implicit in the study of lake ice aggregates by Paerl and Priscu (1998) and could indicate a strong dependence on primary producers by heterotrophic bacteria.

The close balance between PP and $R$ is in stark contrast to the view expressed in Anesio and others' (2009) review, that primary production via photosynthesis often exceeds $R$ by a significant margin. In the following subsection, we show that this balance could compromise aggregate formation and persistence, by linking the carbon fixed by primary 
production to the structural integrity of the aggregate. It also means that primary production might be kept in check by the heterotrophic community and thus prevent thick mats from developing upon the glacier in places where physical processes of removal (e.g. meltwater 'sloughing') are inefficient.

Table 5 shows that a range of different methods has been used to estimate biological production. Method-related differences therefore need to be eliminated before the apparent conflict in the relative importance of PP and $R$ can be better understood. A standard protocol is urgently required. Modern aquatic ecologists appear to favour isotope incorporation, which, in the case of PP, yields similar results to our estimates based upon TDIC (Table 5). However, the duration of incubation reported in the literature varies from hours to whole days and the observed process rates are normalized in a wide range of different ways (e.g. per unit volume, per unit wet mass, per unit dry mass and so on). The situation is the same with estimates of community respiration. It is therefore our view that future in situ incubations should be undertaken in light and dark chambers for intervals of whole days and the results normalized for dry mass. The organic-matter content of the dry debris should also be reported and a range of other assays considered (e.g. chlorophyll content).

\section{Cryoconite aggregate formation and composition}

DNA sequencing analysis of Longyearbreen cryoconite collected during our study and others, and further microscopy showed that the filaments visible in Figure 8 are dominated by cyanobacteria, since no abundant filamentous eukarya (e.g. filamentous algae) could be found (Cameron, unpublished data). The analysis of DAPI-stained cryoconite aggregates implicates these filamentous cyanobacteria in the process of aggregate formation for two key reasons: first they appear woven around the particles and can therefore physically bind them together, and second, they produce a 'glue-like' extracellular polymeric substance (EPS) that chemically binds to mineral surfaces (Paerl and Priscu, 1998; Pereira and others, 2009). Other microorganisms with the capacity to produce EPS substances were also detected by the DNA sequencing, some of which were non-filamentous microalgae with the capacity to contribute to primary production (Cameron and others, unpublished data). However, the abundance of cyanobacteria was notable and they are a well-known phylum in the cryoconite ecosystems of glacial environments, including Svalbard, Canada, Asia and Antarctica (Mueller and others, 2001; Takeuchi and others, 2001a,b; Christner and others, 2003; Porazinska and others, 2004; Stibal and others, 2006; Stibal and Tranter, 2007).

The distribution of the filamentous microorganisms in Figure 8 suggests that much of the cyanobacterial photosynthesis takes place just below the surface of the aggregate. Here the photosynthesis apparatus of the cyanobacteria might be protected from potentially damaging UV light intensities upon the surface of Longyearbreen. Figure 8 also suggests that the 'deeper' filaments might photosynthesize through translucent sand particles in a manner not dissimilar to lithobiontic communities in Antarctic sandstones (Vincent, 1988) or beneath large quartz clasts in hot deserts (Schlesinger and others, 2003). However, there was no pattern in the distribution of filaments around the cryoconite. We believe this is due to light scattering in the ice and aggregate rolling, both of which enable photosynthesis all around the cryoconite. The distribution of cyanobacteria all around cryoconite was also found in Takeuchi and others' $(2001 a, b)$ studies of Canadian and Asian glaciers. In the case of the Asian glacier study, the intensity of cyanobacterial fluorescence around the surface of the aggregate appeared greater than in our study (at least for one aggregate), suggesting that a very high cyanobacterial biomass can be present upon some glaciers.

\section{Aggregate distribution and mobility across the ice}

The distribution of cryoconite was considerably heterogeneous over the ablation area of Longyearbreen, as has been found on other Svalbard glaciers (Hodson and others, 2007). For example, an analysis of six surface ice samples $\left(\sim 0.03 \mathrm{~m}^{2}\right)$ collected during the present study showed cryoconite mass loading between 10.3 and $102 \mathrm{~g} \mathrm{~m}^{-2}$ (mean $68.9 \mathrm{~g} \mathrm{~m}^{-2}$ and standard deviation $75.3 \mathrm{~g} \mathrm{~m}^{-2}$; Bøggild, unpublished data). This range may be compared to the Cryoconite Patch, where the time-lapse images recorded a decrease in cover from $12 \%$ to $7 \%$, corresponding to $\sim 150$ and $90 \mathrm{~g} \mathrm{~m}^{-2}$ respectively. These mass loading estimates are therefore comparable to the lower end of the global range of $100-4400 \mathrm{~g} \mathrm{~m}^{-2}$ identified by Takeuchi and Li (2008) and Anesio and others (2009).

Cryoconite mobilization by meltwater can be likened to tumbleweed moving in the wind because the aggregate particles roll over the ice surface to colonize new areas. However, unlike tumbleweeds, Figure 8 suggests that both photosynthesis and respiration can continue while they are in motion. When they rest at a new location, the process of cryoconite hole formation can begin if a sufficient mass has accumulated (Hodson and others, 2008). We hoped that the Cryoconite Patch time-lapse images would capture this cycle. However, instead they merely captured a sequence of stochastic, short-lived mass transfer events over a distance of $<1 \mathrm{~m}$. These transport rates mean that cryoconite aggregates, like those in the Cryoconite Patch, are easily capable of remaining active upon the glacier for $>1$ year, provided they can avoid major supraglacial streams and survive freezing during the intervening winter. However, in spite of the inefficient transport processes, Figure 3 shows that $0.5 \mathrm{~m}$ w.e. of melting recorded at the Cryoconite Plot caused a significant decline in cryoconite cover during this study. The slope of a linear regression model applied to Figure 3 indicates a daily mass transfer rate of $\sim 2 \%$ of the initial cryoconite cover each day (or $\sim-3.3 \mathrm{~g} \mathrm{~m}^{-2} \mathrm{~d}^{-1}$ ). This is about seven orders of magnitude greater than the mass gained by primary production $\left(\sim 5 \times 10^{-7} \mathrm{~g} \mathrm{~m}^{-2} \mathrm{~d}^{-1}\right.$ using the average PP estimate from Figure 6 and a dry mass to carbon ratio of 2; Loferer-Krössbacher and others, 1998). Therefore primary production is an insignificant term in the mass budget of cryoconite on this glacier (even before the role of heterotrophic microorganisms is considered; cf. Stibal and others, 2008), because rates of biomass accumulation are far lower than physical processes of cryoconite redistribution by meltwater. The implication therefore is that biological activity influences the albedo and debris budget of the ice surface almost entirely as a consequence of the aggregation process. The removal of cryoconite's fine, constituent particles by meltwater flow would be far more easily achieved if biological activity did not invest energy 
into EPS production and physically bind the particles together.

\section{CONCLUSIONS}

We have described how microbial processes result in the formation of mineral-organic aggregates referred to for some time as 'cryoconite'. These aggregates often dominate the visible debris layer that accumulates upon glaciers away from their moraines and margins. Time-lapse images also suggest they may persist for years rather than days, providing time for a sophisticated ecosystem to evolve within them. Their structure and biological activity means that a microbial control upon the retention of fine, aeolian-grade particles exists, adding greater complexity to the relationship between impurities, albedo and melt upon glaciers. Cyanobacteria appear to play a central role in this retention process because they are abundant, capable of new growth by photosynthesis and able to produce EPS that cements mineral grains together. Rates of primary production within cryoconite holes demonstrated significant biomass growth throughout the summer, ranging from 2.1 to $25.7 \mu g \mathrm{Cg}^{-1} \mathrm{~d}^{-1}$. Therefore, it is important to establish whether the carbon demanded by heterotrophs is derived from the primary producers (e.g. EPS), because this poses a potential threat to aggregate stability and longevity. Thus biological processes, in conjunction with meltwater export, most likely explain why drastic changes in the surface albedo of glaciers are not caused by prolonged primary production over successive summers. In fact we found that meltwater export alone is sufficient to prevent this, which is presumably why the thick, continuous cyanobacterial mats found on colder, flatter Arctic and Antarctic ice shelves (e.g. de los Rios and others, 2004; Mueller, 2005) are not more commonplace upon melting glaciers.

\section{ACKNOWLEDGEMENTS}

A.J.H. thanks the Leverhulme Trust for a Research Fellowship RF/4/RFG/2007/0398. We thank M.Á. Jiménez, S. Coulson, M. Kristensen and R. Hermannsen for support in the field. A. Fountain, M. Stibal and N. Takeuchi are thanked for improving the manuscript.

\section{REFERENCES}

Anesio, A.M., A.J. Hodson, A. Fritz, R. Psenner and B. Sattler. 2009. High microbial activity on glaciers: importance to the global carbon cycle. Global Change Biol., 15(4), 955-960.

Bøggild, C.E., R. Brandt, K.J. Brown and S.G. Warren. 2010. The ablation zone in northeast Greenland: ice types, albedos and impurities. J. Glaciol., 56(195), 101-113.

Christner, B.C., B.H. Kvito and J.N. Reeve. 2003. Molecular identification of bacteria and eukarya inhabiting an Antarctic cryoconite hole. Extremophiles, 7(3), 177-183.

Cullity, B.D. 1978. Elements of x-ray diffraction. Second edition. Reading, MA, Addison-Wesley.

De los Ríos, A., C. Ascaso, J. Wierzchos, E. Fernández-Valiente and A. Quesada. 2004. Microstructural characterization of cyanobacterial mats from the McMurdo Ice Shelf, Antarctica. Appl. Environ. Microbiol., 70(1), 569-580.

Fountain, A.G. and M. Tranter. 2008. Introduction to special section on microcosms in ice: the biogeochemistry of cryoconite holes. J. Geophys. Res., 113(G2), G02S91. (10.1029/ 2008JG000698.)
Fountain, A.G., M. Tranter, T.H. Nylen, K.J. Lewis and D.R. Mueller. 2004. Evolution of cryoconite holes and their contribution to meltwater runoff from glaciers in the McMurdo Dry Valleys, Antarctica. J. Glaciol., 50(168), 35-45.

Gale, S.J. and P.J. Hoare. 1991. Quaternary sediments. London, Belhaven Press.

Hasnain, S.I. and R.J. Thayyen. 1999. Controls on the major-ion chemistry of the Dokriani glacier meltwaters, Ganga basin, Garhwal Himalaya, India. J. Glaciol., 45(149), 87-92.

Hodson, A., J. Kohler and M. Brinkhaus. 2005. Multi-year water and surface energy budget of a high-latitude polythermal glacier: evidence for overwinter storage in a dynamic subglacial reservoir. Ann. Glaciol., 42, 42-46.

Hodson, A.J. and 10 others. 2007. A glacier respires: quantifying the distribution and respiration $\mathrm{CO}_{2}$ flux of cryoconite across an entire Arctic supraglacial ecosystem. J. Geophys. Res., 112(G4), G04S36. (10.1029/2007JG000452.)

Hodson, A. and 7 others. 2008. Glacial ecosystems. Ecol. Monogr., 78(1), 41-67.

Irvine-Fynn, T.D.L., J.W. Bridge and A.J. Hodson. 2010. Rapid quantification of cryoconite: granule geometry and in situ supraglacial areal extents. J. Glaciol. 56(196), 297-308.

Kohshima, S., K. Seko and Y. Yoshimura. 1993. Biotic acceleration of glacier melting in Yala Glacier, Langtang region, Nepal Himalaya. IAHS Publ. 218 (Symposium at Kathmandu 1992 Snow and Glacier Hydrology), 309-316.

Loferer-Krössbacher, M., J. Klima and R. Psenner. 1998. Determination of bacterial cell dry mass by transmission electron microscopy and densitometric image analysis. Appl. Environ. Microbiol., 64(2), 688-694.

MacDonell, S. and S. Fitzsimons. 2008. The formation and hydrological significance of cryoconite holes. Progr. Phys. Geogr., 32(6), 595-610.

Madejová, J. 2003. FTIR techniques in clay mineral studies. Vib. Spectrosc., 31(1), 1-10.

Mueller, D.R. 2005. Structure et dynamique des cryo-écosystèmes: plates-formes de glace nordiques. (PhD thesis, Université Laval, Québec.)

Mueller, D.R., W.F. Vincent, W.H. Pollard and C.H. Fritsen. 2001. Glacial cryoconite ecosystems: a bipolar comparison of algal communities and habitats. Nova Hedwigia, 123, 173-197.

Paerl, H.W. and J.C. Priscu. 1998. Microbial phototrophic, heterotrophic, and diazotrophic activities associated with aggregates in the permanent ice cover of Lake Bonney, Antarctica. Microbial Ecol., 36(3), 221-230.

Pereira, S., A. Zille, E. Micheletti, P. Moradas-Ferreira, R. de Philippis and P. Tamagnini. 2009. Complexity of cyanobacterial exopolysaccharides: composition, structures, inducing factors and putative genes involved in their biosynthesis and assembly. FEMS Microbiol. Rev., 33(5), 917-941.

Porazinska, D.L., A.G. Fountain, T.H. Nylen, M. Tranter, R.A. Virginia and D.H. Wall. 2004. The biodiversity and biogeochemistry of cryoconite holes from McMurdo Dry Valley glaciers, Antarctica. Arct. Antarct. Alp. Res., 36(1), 84-91.

Ruffell, A. and P. Wiltshire. 2004. Conjunctive use of quantitative and qualitative X-ray diffraction analysis of soils and rocks for forensic analysis. Forensic Sci. Int., 145(1), 13-23.

Schlesinger, W.H., J.S. Pippen, M.D. Wallenstein, K.S. Hofmockel, D.M. Klepeis and B.E. Mahall. 2003. Community composition and photosynthesis by photoautotrophs under quartz pebbles, southern Mojave Desert. Ecology, 84(12), 3222-3231.

Stibal, M. and M. Tranter. 2007. Laboratory investigation of inorganic carbon uptake by cryoconite debris from Werenskioldbreen, Svalbard. J. Geophys. Res., 112(G4), G04S33. (10.1029/2007JG000429.)

Stibal, M., M. Šabacká and K. Kaštovská. 2006. Microbial communities on glacier surfaces in Svalbard: impact of physical 
and chemical properties on abundance and structure of cyanobacteria and algae. Microbial Ecol., 52(4), 644-654.

Stibal, M., M. Tranter, L.G. Benning and J. Řehák. 2008. Microbial primary production on an Arctic glacier is insignificant in comparison with allochthonous organic carbon input. Environ. Microbiol., 10(8), 2172-2178.

Takeuchi, N. 2002. Optical characteristics of cryoconite (surface dust) on glaciers: the relationship between light absorbency and the property of organic matter contained in the cryoconite. Ann. Glaciol., 34, 409-414.

Takeuchi, N. 2009. Temporal and spatial variations in spectral reflectance and characteristics of surface dust on Gulkana Glacier, Alaska Range. J. Glaciol., 55(192), 701-709.

Takeuchi, N. and Z. Li. 2008. Characteristics of surface dust on Ürümqi Glacier No. 1 in the Tien Shan Mountains, China. Arct. Antarct. Alp. Res., 40(4), 744-750.
Takeuchi, N., S. Kohshima, Y. Yoshimura, K. Seko and K. Fujita. 2000. Characteristics of cryoconite holes on a Himalayan glacier, Yala Glacier central Nepal. Bull. Glaciol. Res., 17, 51-59.

Takeuchi, N., S. Kohshima, K. Goto-Azuma and R.M. Koerner. 2001a. Biological characteristics of dark colored material (cryoconite) on Canadian Arctic glaciers (Devon and Penny ice caps). Mem. Natl Inst. Polar Res., Special Issue 54, 495-505.

Takeuchi, N., S. Kohshima and K. Seko. 2001b. Structure, formation, and darkening process of albedo-reducing material (cryoconite) on a Himalayan glacier: a granular algal mat growing on the glacier. Arct. Antarct. Alp. Res., 33(2), 115-122.

Yde, J.C., M. Riger-Kusk, H.H. Christiansen, N.T. Knudsen and O. Humlum. 2008. Hydrochemical characteristics of bulk meltwater from an entire ablation season, Longyearbreen, Svalbard. J. Glaciol., 54(185), 259-272.

MS received 20 November 2009 and accepted in revised form 23 March 2010 